\title{
Effect of Rehabilitation in Combination with Hyperbaric Oxygen Treatment on the Secretion of Neurotrophic Factors and Oxidative Stress in Recovery Phase of Cerebral Infarction Patients
}

\author{
YING WANG, SHUQING YUAN ${ }^{1}$, XUEHUA MA² AND XIANFENG TIAN ${ }^{3 *}$
}

Department of Household Management, Heze Domestic Professional College, ${ }^{1}$ Department of Obstetrics and Gynecology, Shan County Maternal and Child Health Hospital of Shandong Province, ${ }^{2}$ Department of Ultrasonography, Shan County Central Hospital of Shandong Province, 3 Department of Midwifery, Heze Domestic Professional College, Heze, Shandong 274300, China

\section{Wang et al.: Rehabilitation in Combination with Hyperbaric Oxygen Treatment}

This research study was conducted to elucidate the effect of rehabilitation in combination with hyperbaric oxygen treatment on the secretion of neurotrophic factors and oxidative stress in recovery phase of cerebral infarction patients. A total of 120 cerebral infarction patients undergoing the treatment in recovery phase between June 2017 and May 2019 were randomized into the control group and the experiment group, with 60 patients in each group. In the control group, patients took the regular rehabilitation, while those in the experiment group performed the rehabilitation in combination with hyperbaric oxygen treatment. At admission $\left(\mathrm{T}_{0}\right)$ and after $14 \mathrm{~d}$ of treatment $\left(\mathrm{T}_{1}\right)$, we detected the differences of the level's neurotrophic factors, neurotransmitters and indicators of oxidative stress by comparison. At $T_{0}$, comparison of the neurotrophic factors, neurotransmitters and indicators of oxidative stress showed no significant differences between two groups. At $\mathrm{T}_{1}$, patients in the experiment group experienced sharp decreases in myelin basic protein and neuron specific enolase levels and increase in nerve growth factor as compared with their counterparts in the control group; in serum, the level of glutamic acid in the experiment group was lower than that in the control group, while $\gamma$-aminobutyric acid showed the totally opposite change; in terms of the indicators of oxidative stress, the levels of reactive oxygen species and lipid hydrogen peroxide were lowered in the experiment group, with increases in the levels of catalase and superoxide dismutase when comparing with the control group. For treatment of cerebral infarction patients in recovery phase, rehabilitation in combination with hyperbaric oxygen treatment can optimize the nerve function while inhibit the general oxidative stress responses.

Key words: Oxidative stress, cerebral infarction, rehabilitation, hyperbaric oxygenation, neurotransmitter agents

Cerebral infarction, a frequent cardio- and cerebrovascular disease, is manifested by the high incidence rate, morbidity rate and mortality rate. As the modern medicine advances, the mortality rate of cerebral infarction is decreasing annually, but with an increasing morbidity rate and about 30 to $36 \%$ of patients still suffer from the dysfunction of upper limbs at 6 mo after onset or longer ${ }^{[1]}$. Therapeutic regimen in recovery period of cerebral infarction directly reflects the morbidity and life quality of patients, and rehabilitation, as the major method for treatment, includes the targeted training for motor, linguistic and thinking functions, but the improvement in some patients remains poor ${ }^{[2,3]}$. Hyperbaric oxygen treatment refers to the inhalation of oxygen under the pressure over one barometric pressure, providing novel thought for the treatment of patients with nerve injury, and improving the postoperative nerve function as per the current evidence ${ }^{[4]}$. Insufficient intake of oxygen is the major cause for the failure in recovery of motor function of limbs or cognitive function in cerebral infarction patients. Thus, in this study, we selected the hyperbaric oxygen treatment as auxiliary method for treatment of the patients with cerebral infarction, so as to identify the effect on the neurological function and oxidative stress of patients and provide reference for the treatment

*Address for correspondence

E-mail: xun442@sina.com 
of other patients. A total of 120 cerebral infarction patients undergoing the treatment in recovery phase between June 2017 and May 2019 were randomized into the control group and the experiment group, with 60 patients in each group. In the control group, there were 33 males and 27 females, aged from 49 to $72 \mathrm{y}$ old; in the experiment group, there were 32 males and 28 females, aged from 51 to 73 y old. Differences regarding the baseline data showed no statistical significance $(p>0.05)$, suggesting that the data were comparable. Inclusive criteria-Patients with cerebral infarction that was diagnosed by head Computed tomography (CT) and stabilized after positive treatment; Patients with the first onset of cerebral infarction; Patients who completed all treatment and relevant examination as required. Exclusive criteria-Patients with the history of hyperbaric oxygen treatment; Patients with Alzheimer's disease, Parkinson's disease or other brain diseases prior to the attack of cerebral infarction; Patients complicated with the mental diseases, including depression, prior to the cerebral infarction; Patients complicated with the general infectious diseases. Patients in two groups took the regular drugs of neurology department for lipidlowering therapy, blood-pressure-lowering therapy, anti-coagulation therapy, anti-platelet therapy and improvement of microcirculation. Additionally, they were further required to take the regular rehabilitation, including posturing, walking, training for daily activity and training for diet and drinking and linguistic training. Furthermore, patients in the experiment group took hyperbaric oxygen treatment as follow: At the 2 nd $d$ after admission, hyperbaric oxygen treatment was initiated by pressuring for $30 \mathrm{~min}$ to $0.2 \mathrm{MPa}$ and following $60 \mathrm{~min}$ of oxygen inhalation, patients took rest for $15 \mathrm{~min}$, followed by reducing the pressure for 20 to $30 \mathrm{~min}$. This treatment was conducted once per $\mathrm{d}$, lasting for $14 \mathrm{~d}$. At admission (T0) and after $14 \mathrm{~d}$ of treatment (T1), we collected the fasting peripheral blood samples in the morning (7:00 a.m.-9:00 a.m.) from the patients in two groups for anti-coagulation treatment, followed by centrifugation to isolate the serum in supernatant for later use. Enzyme-linked immunosorbent assay (ELISA) kits were applied to detect the levels of following indicators: myelin basic protein (MBP), neuron specific enolase (NSE), nerve growth factor (NGF), reactive oxygen species (ROS), lipid hydrogen peroxide (LHP), catalase (CAT) and superoxide dismutase (SOD). Radioimmunoassay was performed to detect the levels of neurotransmitters in serum, including glutamic acid (Glu) and $\gamma$-aminobutyric acid (GABA). SPSS 25.0 software was used to process the data in this study. Measurement data, including the levels of neurotrophic factors, neurotransmitters and indicators of oxidative stress, were shown in mean \pm standard deviation, and compared by use of $t$ test. $p<0.05$ suggested the statistical significance of the difference. At $\mathrm{T}_{0}$, comparison of the neurotrophic factors, including MBP, NSE and NGF, showed no significant differences between two groups $(p>0.05)$. At $\mathrm{T}_{1}$, levels of MBP and NSE in serum of patients in two groups were significantly lower than those at $\mathrm{T}_{0}$, but the NGF level was higher. Furthermore, levels of MBP and NSE in serum of patients in the experiment group were all lower than those in the control group, while NGF level was higher $(\mathrm{p}<0.05$; Table 1$)$. At $\mathrm{T}_{0}$, comparison of the neurotransmitters, including Glu and GABA, showed no significant differences between two groups $(\mathrm{p}>0.05)$. At $\mathrm{T}_{1}$, levels of Glu in serum of patients in two groups were significantly lower than those at $\mathrm{T}_{0}$, but the GABA level was higher. Furthermore, levels of Glu in serum of patients in the experiment group were all lower than those in the control group, while GABA level was higher $(\mathrm{p}<0.05$; Table 2$)$. At $\mathrm{T}_{0}$, comparison of the neurotransmitters, including ROS, LHP, CAT and SOD, showed no significant differences between two groups ( $p>0.05$ ). At $T_{1}$, levels of ROS and LHP in serum of patients in two groups were significantly lower than those at $\mathrm{T}_{0}$, but the CAT and SOD levels were higher. Furthermore, levels of ROS and LHP in serum of patients in the experiment group were all lower than those in the control group, while CAT and SOD levels were higher $(\mathrm{p}<0.05$; Table 3$)$. Cerebral infarction is a kind of regional disorder in blood supply in brain tissues caused by multiple factors, usually resulting in the ischemic or hypoxic responses of neurons, dysfunction and irreversible necrosis, and finally evolving into the dysfunction of the ischemiclesion-corresponded somatic region ${ }^{[5,6]}$. Following the treatment for acute phase, cerebral infarction patients come into the stable phase that is the best period for the recovery of somatic/recognitive function. Rehabilitation regimen directly determines the long-term life quality of patients. In addition to the regular limb functions, function of deglutition or linguistic function, thorough optimization of the oxygen uptake of neurons and accelerating the metabolism are the major methods facilitating the recovery of patients from cerebral infarction. Hyperbaric oxygen treatment, as the mostly concerned method to increase the concentration and pressure of oxygen uptake, is believed to be a reliable method to promote the recovery of cerebral infarction 
patients $^{[7-9]}$. In this study, we compared the effect of treatment with or without hyperbaric oxygen treatment on the neurotrophic factors and indicators of oxidative stress of patients in the recovery period of cerebral infarction, thereby clarifying the availability and efficiency of this auxiliary therapeutic regimen. The function damage to neurons caused by the cerebral infarction can further give rise to the variations in the secretion of multiple neurotrophic factors, which, thus, serve as the sensitive indicators to evaluate the nerve damage. MBP is the major protein constituting the myelin sheath in central nerve system, with a high nerve-specificity, and in case of damage to the structure of myelin sheath or blood-brain barrier, the level of MBP in serum is increased ${ }^{[10,11]}$. NSE is a kind of enolase involved in the glycolytic pathway, mainly expressed in nervous tissues, and the variation in level of NSE reflect the outcome of cerebral infarction patients ${ }^{[12,13]}$. NGF, as the first-discovered factor nourishing the nerves and promoting the growth of axons, is in negative association with the damage to the nerves ${ }^{[14]}$. As indicated by this study, we found that as compared with the levels at $\mathrm{T}_{0}$, levels of MBP and NSE in serum at $\mathrm{T}_{1}$ in two groups were decreased sharply, with an increase in NGF level; further comparison with the control group revealed that at $\mathrm{T}_{1}$, patients had lower levels of MBP and NSE in the experiment group, but higher level of NGF, suggesting that hyperbaric oxygen treatment may excel in optimizing the nerve function of cerebral infarction patients. Attack of cerebral infarction damages the homeostasis inside the neurons, and the variations in expression of neurotransmitters further give rise to the nerve injuries. Glu, a kind of excitatory neurotransmitter in human, is depolarized due the cerebral infarctioninduced ischemia and hypoxia in neurons, resulting in the calcium influx and increase in the synthesis and secretion of Glu ${ }^{[15,16]}$. GABA, a kind of inhibitory amino acid, has been shown to be decreased in expression of patients with hemorrhage or cerebral infarction and the administration of GABA agonist contributes to the recovery of nerve function of patients ${ }^{[17,18]}$. Results of this study discovered that as compared with the levels at $\mathrm{T}_{0}$, levels of Glu in serum at $\mathrm{T}_{1}$ in two groups were decreased sharply, with an increase in GABA level; further comparison with the control group revealed that at $\mathrm{T}_{1}$, patients had lower levels of Glu in the experiment group, but higher level of GABA, suggesting that hyperbaric oxygen treatment is efficiently in balancing the expressions between the excitatory amino acids and inhibitory amino acids to promote the recovery of nerve function for cerebral infarction patients in recovery phase. Ischemia and hypoxia of the nerve tissues resulted from the cerebral infarction can directly induce the oxidative stress and the resultant massive generation of ROS further aggravates the function damage to neurons, promotes the peroxidation of lipid, and increases the consumption of CAT and SOD, thereby influencing on the balance between oxidation and antioxidation; thus, it is believed to be the major cause for the disease progression of cerebral infarction ${ }^{[19,20]}$. In this study, as compared with the levels at $\mathrm{T}_{0}$, levels of ROS and LHP in serum at $T_{1}$ in two groups were decreased sharply, with increases in CAT and SOD levels; further comparison with the control group revealed that at $\mathrm{T}_{1}$, patients had lower levels of ROS and LHP in the experiment group, but higher levels of CAT and SOD, suggesting that hyperbaric oxygen treatment is efficiently in suppressing the oxidative stress for cerebral infarction patients in recovery phase. Hence, we infer that such a change may result from the eradication of the hypoxia after the oxygen uptake of neurons is increased. Overall, for cerebral infarction patients in recovery phase, hyperbaric oxygen treatment in combination with the regular rehabilitation can effectively balance the secretion of neurotrophic factors, optimize the nerve function while suppress the oxidative stress responses. Thus, this strategy is positive to the recovery of patients.

TABLE 1: COMPARISON OF THE LEVELS OF THE NEUROTROPHIC FACTORS IN SERUM OF PATIENTS IN TWO GROUPS $(n=60)$

\begin{tabular}{lcccccc}
\hline \multirow{2}{*}{ Group } & \multicolumn{2}{c}{$\mathrm{MBP}(\mathrm{pg} / \mathrm{mL})$} & \multicolumn{2}{c}{$\mathrm{NSE}(\mu \mathrm{g} / \mathrm{L})$} & \multicolumn{2}{c}{$\mathrm{NGF}(\mathrm{ng} / \mathrm{L})$} \\
\cline { 2 - 7 } & $\mathrm{T}_{0}$ & $\mathrm{~T}_{1}$ & $\mathrm{~T}_{0}$ & $\mathrm{~T}_{1}$ & $\mathrm{~T}_{0}$ & $\mathrm{~T}_{1}$ \\
\hline Control group & $29.37 \pm 3.53$ & $19.72 \pm 2.65^{*}$ & $17.50 \pm 2.86$ & $11.54 \pm 1.77^{*}$ & $301.28 \pm 43.83$ & $457.19 \pm 59.67^{*}$ \\
Experiment & $29.42 \pm 3.49$ & $11.68 \pm 1.76^{*}$ & $17.68 \pm 2.70$ & $6.08 \pm 0.69^{*}$ & $305.62 \pm 38.94$ & $685.43 \pm 75.97^{*}$ \\
group & 0.216 & 10.284 & 0.177 & 18.395 & 0.395 & 24.382 \\
$\mathrm{t}$ & $>0.05$ & $<0.05$ & $>0.05$ & $<0.05$ & $>0.05$ & $<0.05$ \\
$\mathrm{p}$ & & & &
\end{tabular}

Mean \pm standard deviation.

Note: ${ }^{*} p<0.05$ vs. the levels at $T_{0}$ in the same group 
TABLE 2: COMPARISON OF THE LEVELS OF NEUROTRANSMITTERS IN SERUM OF PATIENTS BETWEEN TWO GROUPS $(n=60)$

\begin{tabular}{lcccc}
\hline \multirow{2}{*}{ Group } & \multicolumn{2}{c}{ Glu } & \multicolumn{3}{c}{ GABA } \\
\cline { 2 - 5 } & $\mathrm{T}_{0}$ & $\mathrm{~T}_{1}$ & $\mathrm{~T}_{0}$ & $\mathrm{~T}_{1}$ \\
\hline Control group & $79.37 \pm 9.16$ & $51.29 \pm 6.38^{*}$ & $54.29 \pm 6.20$ & $71.64 \pm 8.09^{*}$ \\
Experiment group & $78.96 \pm 8.77$ & $40.67 \pm 5.95^{*}$ & $54.52 \pm 5.88$ & $90.75 \pm 9.26^{*}$ \\
$\mathrm{t}$ & 0.22 & 13.295 & 0.177 & 10.738 \\
$\mathrm{p}$ & $>0.05$ & $<0.05$ & $>0.05$ & $<0.05$ \\
\hline
\end{tabular}

Mean \pm standard deviation.

Note: ${ }^{*}<0.05$ vs. the levels at $T_{0}$ in the same group

TABLE 3: COMPARISON OF THE INDICATORS OF OXIDATIVE STRESS IN SERUM OF PATIENTS BETWEEN TWO GROUPS $(n=60)$

\begin{tabular}{lcccccccc}
\hline \multirow{2}{*}{ Group } & \multicolumn{2}{c}{$\mathrm{ROS}(\mathrm{U} / \mathrm{mL})$} & \multicolumn{2}{c}{ LHP $(\mu \mathrm{mol} / \mathrm{L})$} & \multicolumn{2}{c}{ CAT $(\mathrm{U} / \mathrm{mL})$} & \multicolumn{2}{c}{ SOD $(\mathrm{U} / \mathrm{L})$} \\
\cline { 2 - 8 } & $\mathrm{T}_{0}$ & $\mathrm{~T}_{1}$ & $\mathrm{~T}_{0}$ & $\mathrm{~T}_{1}$ & $\mathrm{~T}_{0}$ & $\mathrm{~T}_{1}$ & $\mathrm{~T}_{0}$ & $\mathrm{~T}_{1}$ \\
\hline $\begin{array}{l}\text { Control } \\
\text { group }\end{array}$ & $742.92 \pm 85.64$ & $518.35 \pm 6.30^{*}$ & $490.26 \pm 54.72$ & $351.24 \pm 39.77^{*}$ & $4.29 \pm 0.48$ & $5.18 \pm 0.59^{*}$ & $40.29 \pm 4.96$ & $51.94 \pm 6.26^{*}$ \\
$\begin{array}{l}\text { Experiment } \\
\text { group }\end{array}$ & $739.67 \pm 83.48$ & $302.17 \pm 34.79^{*}$ & $492.65 \pm 58.96$ & $232.85 \pm 29.78^{*}$ & $4.27 \pm 0.50$ & $7.95 \pm 0.87^{*}$ & $40.77 \pm 4.90$ & $67.89 \pm 8.54^{*}$ \\
$\mathrm{t}$ & 0.282 & 15.393 & 0.177 & 18.973 & 0.573 & 6.388 & 0.262 & 8.973 \\
$\mathrm{p}$ & $>0.05$ & $<0.05$ & $>0.05$ & $<0.05$ & $>0.05$ & $<0.05$ & $>0.05$ & $<0.05$ \\
\hline
\end{tabular}

Mean \pm standard deviation.

Note: ${ }^{*}<0.05$ vs. the levels at $T_{0}$ in the same group

\section{Conflict of interests:}

The authors declared no conflicts of interest.

\section{REFERENCES}

1. Zhou LJ, Wang W, Zhao Y, Liu CF, Zhang XJ, Liu ZS, et al. Blood oxygenation level-dependent functional magnetic resonance imaging in early days: Correlation between passive activation and motor recovery after unilateral striatocapsular cerebral infarction. J Stroke Cerebrovasc Dis 2017;26:265261.

2. Meng ZY, Song WQ. Low frequency repetitive transcranial magnetic stimulation improves motor dysfunction after cerebral infarction. Neural Regen Res 2017;12:610-13.

3. Hu Q, Manaenko A, Bian H, Guo Z, Huang JL, Guo ZN, et al. Hyperbaric oxygen reduces infarction volume and hemorrhagic transformation through ATP/NAD+/Sirt1 pathway in hyperglycemic middle cerebral artery occlusion rats. Stroke 2017;48:1655-64.

4. Yang ZS, Mu J. Co-administration of tissue plasminogen activator and hyperbaric oxygen in ischemic stroke: a continued promise for neuroprotection. Medical gas research. 2017;7:68-73.

5. Chang F, Xiong W, Wang D, Liu XZ, Zhang W, Zhang M, et al. Facilitation of ultrasonic microvesicles on homing and molecular mechanism of bone marrow mesenchymal stem cells in cerebral infarction patients. Eur Rev Med Pharmacol Sci 2017;21:3916-23.

6. Kwon I, An S, Kim J, Yang SH, Yoo J, Baek JH, et al. Hemorrhagic transformation after large cerebral infarction in rats pretreated with dabigatran or warfarin. Stroke 2017;48:2865-71.
7. Polzik P, Johansson PI, Hyldegaard O. How biomarkers reflect the prognosis and treatment of necrotising soft tissue infections and the effects of hyperbaric oxygen therapy: the protocol of the prospective cohort PROTREAT study conducted at a tertiary hospital in Copenhagen, Denmark. BMJ open 2017;7:e017805.

8. Sun Q, Wu G, Chen $\mathrm{H}$, Chen L, Chen H, Zhu G, et al. Hyperbaric oxygen protects type II collagen in interleukin-1 $\beta$ induced mandibular condylar chondrocyte via inhibiting the JNK/c-Jun singnaling pathway. Oncotarget 2017;8:60312-23.

9. Iyikesici MS, Slocum AK, Slocum A, Berkarda FB, Kalamian M, Seyfried TN. Efficacy of metabolically supported chemotherapy combined with ketogenic diet, hyperthermia, and hyperbaric oxygen therapy for stage IV triple-negative breast cancer. Cureus 2017;9:e1445.

10. Nejati P, Attar M, Rahimian M, Fathi D, Shahbazi M. Combination of myelin basic protein gene polymorphisms with HLA-DRBI*1501 in Iranian patients with multiple sclerosis. Iran J Immunol 2017;14:231-9.

11. Frolov MA, Likhvantseva VG, Kovelenova IV, Solomatina MV. Significance of anti-myelin basic protein antibodies for ocular hydrodynamic disturbances in primary open-angle glaucoma. Vestn Oftalmol 2017;133:37-43.

12. Park T, Lee YJ, Jeong SH, Choi SK, Jung EJ, Ju YT, et al. Overexpression of neuron-specific enolase as a prognostic factor in patients with gastric cancer. J Gastric Cancer 2017;17:228-36.

13. Huang L, Zhou JG, Yao WX, Tian X, Lv SP, Zhang TY, et al. Systematic review and meta-analysis of the efficacy of serum neuron-specific enolase for early small cell lung cancer screening. Oncotarget 2017;8:64358-72. 
14. Suh YS, Ko KJ, Kim TH, Lee HS, Sung HH, Cho WJ, et al. Potential biomarkers for diagnosis of overactive bladder patients: Urinary nerve growth factor, prostaglandin E2 and adenosine triphosphate. Int Neurol J 2017;21:171-7.

15. Khanna S, Stewart R, Gnyawali S, Harris H, Balch M, Spieldenner $\mathrm{J}$, et al. Phytoestrogen isoflavone intervention to engage the neuroprotective effect of glutamate oxaloacetate transaminase against stroke. FASEB J 2017;31:4533-44.

16. Rink C, Gnyawali S, Stewart R, Teplitsky S, Harris H, Roy S, et al. Glutamate oxaloacetate transaminase enables anaplerotic refilling of TCA cycle intermediates in stroke-affected brain. FASEB J 2017;31:1709-18.

17. Hosinian M, Qujeq D, Ahmadi AA. The relation between GABA and L-arginine levels with some stroke risk factors in acute is chemic stroke Patients. Int J Mol Cell Med 2016;5:100-5.

18. Hiu T, Farzampour Z, Paz JT, Wang EH, Badgely C, Olson A, et al. Enhanced phasic GABA inhibition during the repair phase of stroke: A novel therapeutic target. Brain 2016;139:468-80.
19. Austin V, Crack PJ, Bozinovski S, Miller AA, Vlahos R. COPD and stroke: are systemic inflammation and oxidative stress the missing links? Clin Sci 2016;130:1039-50.

20. Han Z, Shen F, He Y, Degos V, Camus M, Maze M, et al. Correction: activation of $\alpha-7$ nicotinic acetylcholine receptor reduces ischemic stroke injury through reduction of proinflammatory macrophages and oxidative stress. PloS one 2016;11:e0152218.

This is an open access article distributed under the terms of the Creative Commons Attribution-NonCommercial-ShareAlike 3.0 License, which allows others to remix, tweak, and build upon the work non-commercially, as long as the author is credited and the new creations are licensed under the identical terms

This article was originally published in a special issue,
"Trends in Therapeutic Management of Various Clinical
Conditions II" Indian J Pharm Sci 2021:83(2)Spl issue;166-170

